\title{
Erratum to: Fluoroscopy-Guided Percutaneous Vertebral Body Biopsy Using a Novel Drill-Powered Device: Technical Case Series
}

\author{
Adam N. Wallace ${ }^{1} \cdot$ Rafael A. Pacheco ${ }^{1} \cdot$ Anderanik Tomasian $^{1} \cdot$ Andy C. Hsi $^{2}$ \\ Jeremiah Long ${ }^{1} \cdot$ Randy O. Chang ${ }^{3} \cdot$ Jack W. Jennings ${ }^{1}$
}

Published online: 24 November 2015

(C) Springer Science+Business Media New York and the Cardiovascular and Interventional Radiological Society of Europe (CIRSE) 2016

\section{Erratum to: Cardiovasc Intervent Radiol \\ DOI: 10.1007/s00270-015-1216-y}

An error was introduced into the Figure 1 legend by the publisher. After "B", the sentence should read: "The hollow biopsy needle is engaged ...guidance". In the published article, the words "The hollow biopsy needle" are missing from the Figure 1 legend and were transplanted to the end of the paragraph in the Methods section under the subheading "The OnControl System".

The online version of the original article can be found under doi:10.1007/s00270-015-1216-y.

Adam N. Wallace

wallacea@mir.wustl.edu

Rafael A. Pacheco

pachecor@mir.wustl.edu

Anderanik Tomasian

tomasiana@mir.wustl.edu

Andy C. Hsi

hsia@path.wustl.edu

Jeremiah Long

longj@mir.wustl.edu

Randy O. Chang

changr@wusm.wustl.edu

Jack W. Jennings

jenningsj@mir.wustl.edu
Mallinckrodt Institute of Radiology, Washington University School of Medicine, 510 South Kingshighway Boulevard, Saint Louis, MO 63110, USA

2 Division of Anatomic Pathology, Department of Pathology \& Immunology, Washington University School of Medicine, Campus Box 8118, 660 South Euclid Avenue, Saint Louis, MO, USA

Washington University School of Medicine, 660 South Euclid Avenue, St. Louis, MO 63110, USA 